\title{
Root Traits Enhancing Rice Grain Yield under Alternate Wetting and Drying Condition
}

\author{
Nitika Sandhu ${ }^{1}$, Sushil R. Subedi ${ }^{1}$, Ram B. Yadaw ${ }^{2}$, Bedanand Chaudhary ${ }^{2}$, Hari Prasai ${ }^{3}$, \\ Khandakar Iftekharuddaula ${ }^{4}$, Tho Thanak ${ }^{5}$, Vathany Thun ${ }^{5}$, Khushi R. Battan ${ }^{6}$, \\ Mangat Ram ${ }^{6}$, Challa Venkateshwarlu ${ }^{7}$, Vitaliano Lopena ${ }^{1}$, Paquito Pablico ${ }^{1}$, \\ Paul C. Maturan ${ }^{1}$, Ma. Teresa Sta. Cruz ${ }^{1}$, K. Anitha Raman ${ }^{1}$, Bertrand Collard ${ }^{1}$ and \\ Arvind Kumar ${ }^{1 *}$ \\ ${ }^{1}$ International Rice Research Institute, Los Baños, Philippines, ${ }^{2}$ National Rice Research Program, Hardinath, Nepal, \\ ${ }^{3}$ Regional Agriculture Research Station, Tarahara, Nepal, ${ }^{4}$ Bangladesh Rice Research Institute, Gazipur, Bangladesh, \\ ${ }^{5}$ Cambodian Agricultural Research and Development Institute, Phnom Penh, Cambodia, ${ }^{6}$ Rice Research Station, Kaul, India, \\ ${ }^{7}$ South Asia Breeding Hub, International Rice Research Institute, International Crops Research Institute for the Semi-Arid \\ Tropics (ICRISAT), Hyderabad, India
}

OPEN ACCESS

Edited by:

Hussein Shimelis, University of KwaZulu-Natal,

South Africa

Reviewed by:

Karl Kunert,

University of Pretoria, South Africa

Sileshi Gudeta Weldesemayat, EliSil Environmental Consultants,

Zambia

*Correspondence: Arvind Kumar a.kumar@irri.org

Specialty section: This article was submitted to Plant Breeding, a section of the journal Frontiers in Plant Science

Received: 25 July 2017 Accepted: 16 October 2017 Published: 31 October 2017

Citation:

Sandhu N, Subedi SR, Yadaw RB,

Chaudhary $B$, Prasai $H$ Iftekharuddaula $K$, Thanak $T$, Thun $V$, Battan KR, Ram M, Venkateshwarlu C,

Lopena V, Pablico P, Maturan PC, Cruz MTS, Raman KA, Collard B and Kumar A (2017) Root Traits Enhancing

Rice Grain Yield under Alternate Wetting and Drying Condition.

Front. Plant Sci. 8:1879. do: 10.3389/fpls.2017.01879
Reducing water requirements and lowering environmental footprints require attention to minimize risks to food security. The present study was conducted with the aim to identify appropriate root traits enhancing rice grain yield under alternate wetting and drying conditions (AWD) and identify stable, high-yielding genotypes better suited to the AWD across variable ecosystems. Advanced breeding lines, popular rice varieties and drought-tolerant lines were evaluated in a series of 23 experiments conducted in the Philippines, India, Bangladesh, Nepal and Cambodia in 2015 and 2016. A large variation in grain yield under AWD conditions enabled the selection of high-yielding and stable genotypes across locations, seasons and years. Water savings of 5.7-23.4\% were achieved without significant yield penalty across different ecosystems. The mean grain yield of genotypes across locations ranged from 3.5 to $5.6 \mathrm{t} / \mathrm{ha}$ and the mean environment grain yields ranged from 3.7 (Cambodia) to 6.6 (India) t/ha. The best-fitting Finlay-Wilkinson regression model identified eight stable genotypes with mean grain yield of more than $5.0 \mathrm{t} / \mathrm{ha}$ across locations. Multidimensional preference analysis represented the strong association of root traits (nodal root number, root dry weight at 22 and 30 days after transplanting) with grain yield. The genotype IR14L253 outperformed in terms of root traits and high mean grain yield across seasons and six locations. The $1.0 \mathrm{t} / \mathrm{ha}$ yield advantage of IR14L253 over the popular cultivar IR64 under AWD shall encourage farmers to cultivate IR14L253 and also adopt AWD. The results suggest an important role of root architectural traits in term of more number of nodal roots and root dry weight at $10-20 \mathrm{~cm}$ depth on $22-30$ days after transplanting (DAT) in providing yield stability and preventing yield reduction under AWD compared to continuous flooded conditions. Genotypes possessing increased number of nodal roots provided higher yield over IR64 as well as no yield reduction under AWD compared to flooded irrigation. The identification of appropriate root architecture traits at specific depth and specific growth stage shall help breeding programs develop better rice varieties for AWD conditions.

Keywords: alternate wetting and drying, rice, root, water, yield 


\section{INTRODUCTION}

Increased demand of water for household, industry, agriculture and the changing climatic conditions in term of decreasing monsoon rainfall in South Asia and South East-Asia has made water a more valuable commodity than ever before. "More rice with less water" is vital for water-food security and agriculture sustainability (Tuong et al., 2005). Water shortage has a critical impact on the world's food self-sufficiency and security (FAO, 2016). Farmers in Asia depend mostly on monsoon rains. With the existing climatic vulnerability, almost half the planet's population will be living in areas of high water shortage by 2030 (UNCCD, 2014). In the dry season or in an environment with an evaporation rate higher than the precipitation rate, approximately $700-1,500 \mathrm{~mm}$ of water, depending on soil characteristics, is required to produce $1 \mathrm{~kg}$ of rice when using traditional practices of rice cultivation (Bhuiyan, 1992). The actual water requirement for rice crop cultivation is much lower than the amount of water traditionally used (Tuong, 1999; Li et al., 2006). This calls attention to the necessity of developing climate-smart, water-saving irrigation (WSI) technologies that reduce water use, carbon sequestration and greenhouse gas (GHGs) emissions (IRRI, 2009; Yang et al., 2017); and the identification of suitable traits leading resilience (adaptation) and stable high yielding genotypes with high water use efficiency and sustainable productivity.

The alternate wetting and drying (AWD) system of irrigation is one of the most common water-saving techniques in practice (Bouman and Tuong, 2001; Belder et al., 2004; Moya et al., 2004). It deals with the problem of water shortage in irrigated rice cultivation and has the potential to contribute to more sustainable and effective water and energy use. AWD is the practice of allowing the field to periodically dry and rewet throughout the growing season instead of keeping paddies in a permanently flooded state. Depending on the soil's type, texture and characteristics; the climate and the crop's development stage, the AWD cycle (flooded-nonflooded) can vary from 1 to 10 days or even more. AWD is a simple, farmer-friendly practice that uses a single device (a water pipe) designed to observe the water level in a rice field for deciding when to irrigate. Compared to flooded/aerobic cultivation, field leveling is critical when using AWD. AWD can contribute to agricultural sustainability by reducing water use in irrigated rice by $15-30 \%$ (Zhang et al., 2009 ), increasing rice yield by approximately $10 \%$ relative to continuous flooding (Yang et al., 2007; Zhang et al., 2009), boosting nutritional status (Wissuwa et al., 2008), and decreasing toxic elements such as cadmium (Cd) (Yang et al., 2009) and arsenic (As) (Xu et al., 2008; Yang et al., 2017). The Iron (Fe) toxicity because of high availability of Fe under continuously flooded soils as practiced in some of the coastal areas in Asia and Africa can also be reduced using AWD (Cherif et al., 2009).

In some studies, the use of AWD has been shown to provide similar rice yields to those of continuously flooded systems (Yao et al., 2012) or slightly lower yields (Yadav et al., 2012). The amount of water saved involving AWD would in itself be adequate to rationalize any inconsequential yield loss when using this practice. AWD improves or modifies root/shoot growth and activity (Sarkar, 2001; Yang et al., 2009; Yang and Zhang, 2010) and water use efficiency (Tabbal et al., 2002); facilitates further access to water and nutrients at $0-30 \mathrm{~cm}$ soil depth; improves the proportion of productive tillers, alters leaf angle and plant hormone signaling (Davies et al., 2011); and enhances the grain filling rate (Zhang et al., 2010, 2012). AWD technology has a high potential for breeders to develop water-saving and yield-stable rice genotypes by further modifying the root system architecture of presently cultivated rice genotypes. The adaptability of the root system relative to the timing and intensity of fluctuations in soil metric and redox potential will affect the impact of the AWD treatment on nutrient access, whole root system water potential, signaling, resource allocation and partitioning between root and shoot. The critical concerns in the adoption of AWD are the unavailability of adequate knowledge on traits suitable to obtain higher yield under AWD system and the appropriate modification of the root systems of presently available flooded irrigated system adapted genotypes. So far, no rice variety with appropriate root architecture has been developed that produced similar yield across rice growing conditions under AWD. Till date, no study has reported the effect on grain yield under AWD by differences in the root traits at different soil depth and at specific plant growth stage.

The present study was conducted with the aim to identify appropriate root traits enhancing rice grain yield under AWD and identify stable, high-yielding genotypes better suited to the AWD across variable ecosystems. We hypothesized that the rice genotypes with comparatively better root system in the 15-20 $\mathrm{cm}$ root zone shall have stable and high grain yield under AWD compared to genotypes with lesser nodal roots and lower root dry weight.

\section{MATERIALS AND METHODS}

\section{Plant Material and Locations}

The plant material was comprised of advanced breeding lines from irrigated and rainfed breeding programs of International Rice Research Institute (IRRI). The popular rice varieties grown in different countries (PSBRc 52, Matang 1, Matang 9, PSBRc 28, PSBRc 82, BR28, BR29, Janaki, Khao Dawk Mali 105, WS 91, Abhaya, Vasistha, Mahsuri, Teqing, MRQ74, Samba Mahsuri, IR07F287, Fedearroz 50/NSICRc 158, IRRI 143, IRRI 149, IRRI 150, IRRI 168, Apo, Thadokkham 1, NSICRc 138, PSBRc 10, NSICRc 110, MTU1010, and IR64) and drought tolerant breeding lines (IR 77298-14-1-2-10, IR 77298-5-6-18, IR 84984-83-15-18-B-B, IR 81896-B-B-236, IR 78875-176-B-2) were used to develop the advanced breeding lines.

The hybridization program to develop appropriate breeding lines involving the above parents was initiated in 2005DS (Dry Season) with the inclusion of new crosses each successive season. The crossing, selection and advancement scheme is shown in Figure 1. The screening material for AWD experiments includes advanced breeding sister lines from 2005DS (two families), 2006DS (one family), 2006WS (Wet season) (two families), 2007WS (nine families), 2008WS (two families), 2008DS (two families), 2009DS (four families), 


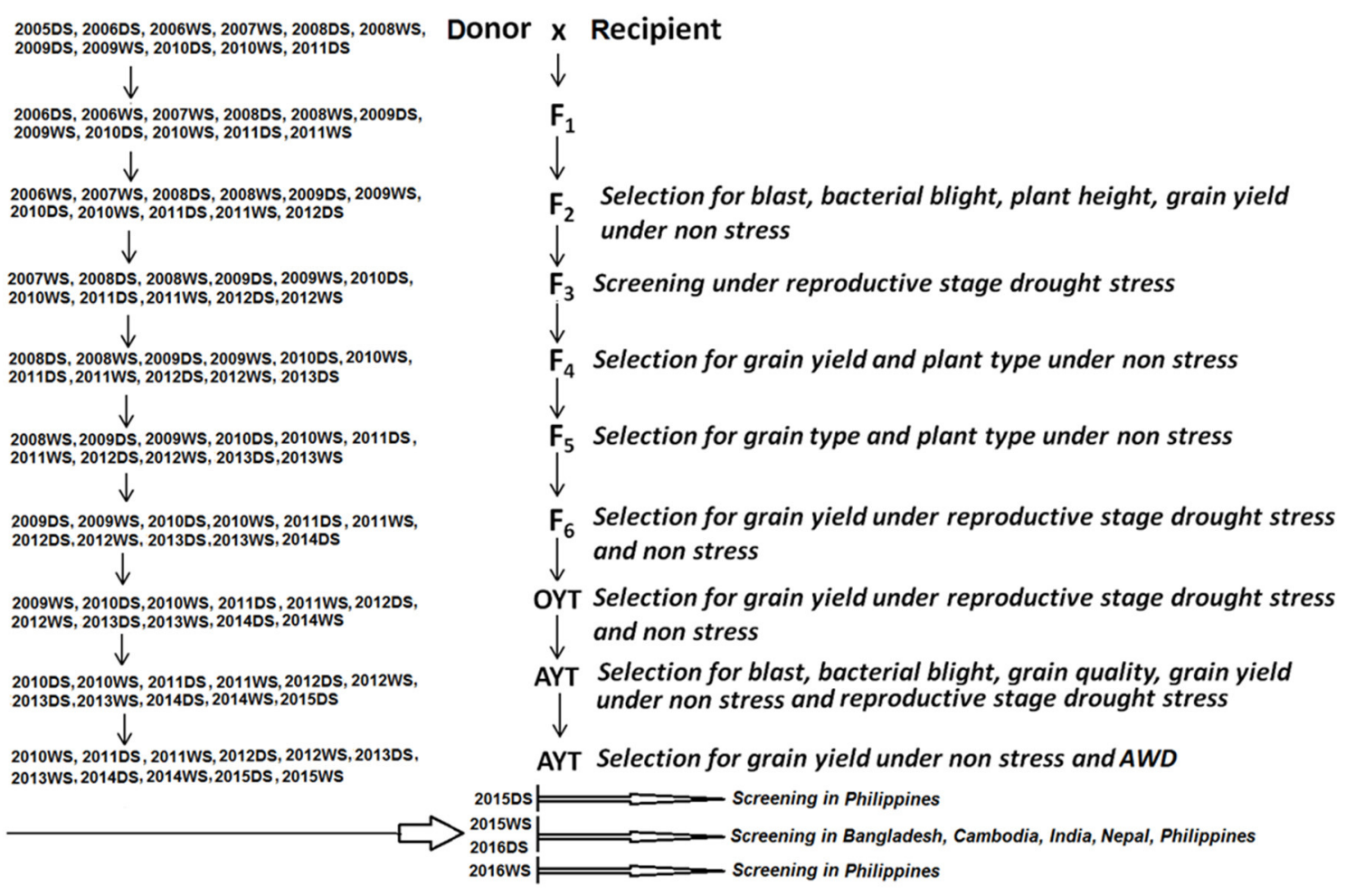

FIGURE 1 | Scheme for the development of advanced breeding lines and selection strategy in generation using a modified conventional breeding approach.

2009WS (four families), 2010DS (ten families), 2010WS (16 families), and 2011DS (15 families) (Supplementary Table 1).

To identify promising yield stable genotypes, a series of 23 experiments were conducted under the AWD system of rice cultivation at the IRRI, Philippines during 2015DS, 2015WS, 2016DS, and 2016WS); IRRI-South Asia Breeding Hub, ICRISAT, Hyderabad, India; Bangladesh Rice Research Institute, BRRI, Gazipur, Bangladesh; National Rice Research Program NRRP, Hardinath, Nepal; Regional Agriculture Research Station, RARS, Tarahara Nepal; and Cambodian Agricultural Research and Development Institute, CARDI, Phnom Penh, Cambodia in 2015WS and 2016DS; at Rice Research Station, Kaul, Haryana (India) in 2016WS. Table 1 shows a detailed description of the number of lines screened for each season under different irrigation and management practices. The lines were selected based on no yield reduction under AWD compared to continuous flooding irrigation system for the successive seasons screening at IRRI. At IRRI, in the 2016DS, four genotypes were selected based on yield stability across treatments and seasons and were screened for root and agronomic traits in 2016WS together with lowland adapted check (IR64).

\section{Agronomic Management and AWD System Implementation}

Along with AWD experiment, a concurrent controlled experiment was undertaken in which approximately $5 \mathrm{~cm}$ of standing water was maintained in the field after transplanting till 10 days before harvesting (Table 1). The detailed description of experiments and management practices is given in Table 1.

The depth of water in the AWD field was measured by installing water pipes $(35 \mathrm{~cm}$ high $\times 20 \mathrm{~cm}$ diameter, with $5 \mathrm{~mm}$ diameter holes and $2 \mathrm{~cm}$ spacing from hole to hole) (Supplementary Figure 1) in zig-zag pattern across field. The water level was maintained at $5 \mathrm{~cm}$ until 15 days after transplanting (DAT). Then AWD cycle was initiated. When the water level dropped to $15 \mathrm{~cm}$ below the soil surface (Supplementary Figures 1, 2), the field was irrigated to the depth of $5 \mathrm{~cm}$. A week before to a week after the peak of flowering, water was maintained to $5 \mathrm{~cm}$ depth to avoid water stress. AWD cycle was re-started after flowering and during grain filling. The number of irrigation events was noted throughout the experiment. Rainfall data were also taken into consideration in calculating the water saving achieved. The amount of water used and water saved (in percentage) were calculated as:

Amount of water used: (Total number of irrigation $\times$ Total area $\times$ Depth of ponding water $)+($ Total rainfall $)$

$$
\% \text { water saving: } \frac{\text { Water used in continuous irrigation (flooded) }- \text { Water used in AWD }}{\text { Water used in continuous irrigation (flooded) }} \times 100
$$




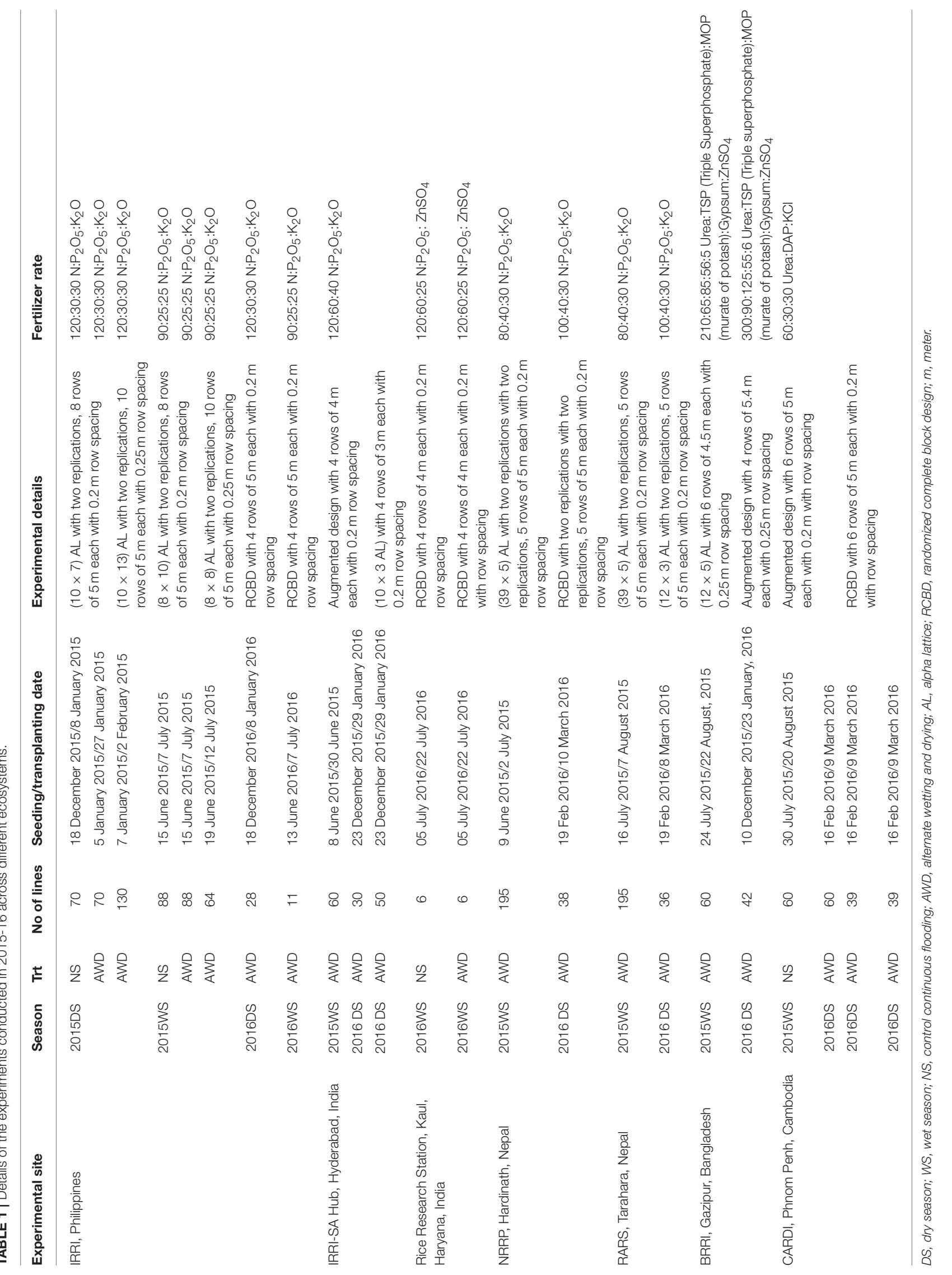




\section{Data Collection}

\section{Agronomic Traits}

The number of days to flowering was recorded when $50 \%$ of the plants in the plot exerted their panicles. At maturity, plant height was measured from the base of the plant to the tip of the highest panicle from three random plants per plot. The harvested grains were threshed and oven dried for 3 days (at $50^{\circ} \mathrm{C}$ ). The grain weight data was normalized to a moisture content of $14 \%$ to estimate grain yield $(\mathrm{t} / \mathrm{ha})$. Similar measurements were done at the locations in India, Bangladesh, Nepal and Cambodia.

\section{Seedling and Root Traits}

During the 2016WS, three seedlings per plot were sampled by digging a hole in the soil using whole plant core sampler at 15,22 , $30 \mathrm{DAT}$ and at $50 \%$ days to flowering (Figure 2). The roots were gently washed over a sieve. The number of nodal roots per plant (NR) was counted manually. The root length (RL) was measured with centimeter scale. The roots and shoots were then separated and shoots were dried in an oven at $60^{\circ} \mathrm{C}$ for 3 days to record root dry weight (RDW) and shoot dry weight (SDW). The relative growth rate (RGR) was calculated in term of shoot dry weight as follows: the genotypes and extracts this as the first principal component (Singh et al., 2001, 2017). The second principal component represents the direction that is most salient to the preferences that are orthogonal to the first principal component).

\section{RESULTS}

\section{Phenotypic Screening across Seasons and Locations}

At IRRI, under non stress (continuous flooding) the mean days to $50 \%$ flowering ranged from 85 to 88 days, mean plant height ranged from 95 to $120 \mathrm{~cm}$ and mean grain yield ranged from 5.3 to 7.4 t/ha. Under AWD conditions the mean days to $50 \%$ flowering ranged from 79 to 89 days, mean plant height from 95 to $121 \mathrm{~cm}$ while mean grain yield from 4.8 to $7.5 \mathrm{t} / \mathrm{ha}$ at IRRI. The trial heritability's for grain yield varied from 0.52 to 0.92 at IRRI (Table 2). At IRRI, 12\% reduction in grain yield was observed under AWD compared to continuous flooding (the control conditions) in 2015DS while in 2015WS, the yield under AWD was 9\% higher than continuous flooding control. The grain yield was $2 \%$ and $6-8 \%$ higher under AWD conditions compared to continuous flooding control conditions in India and

$$
R G R=\left[\frac{\ln (\text { shoot dry weight at sampling } 2)-\ln (\text { shoot dry weight at sampling } 1)}{(\text { date of sampling } 2-\text { date of sampling } 1)}\right]
$$

\section{Data Analysis}

\section{Trial-wise Analysis}

Analysis of variance (ANOVA) for seedling, root and agronomic traits from each trial (site $\times$ year $\times$ season) was performed using the SAS PROC MIXED (Littell et al., 2006) taking replications and blocks within replications as random effects and lines as fixed effects. Broad-sense heritability $(\mathrm{H})$ was estimated as:

$$
H=\frac{\sigma^{2} g}{\sigma^{2} g+\frac{\sigma^{2} e}{r}}
$$

where $\sigma_{g}^{2}$ is the genotypic variance, $\sigma_{e}^{2}$ the error variance, and $r$ the number of replications.

\section{Across Trial Yield Stability Analysis}

The genotypes that were tested in four or more trials under AWD were included in the yield stability analysis. Four conventional stability models with homogenous and heterogeneous error variances were fitted to the genotype $\mathrm{x}$ trial table of means within the mixed model framework Piepho (1999) in which the trials were treated as random and genotypes as fixed. These included (i) Shukla's stability variance model (ii) Finlay-Wilkinson model (iii) Eberhart-Russell model, and (iv) AMMI model. The best-fitting model was selected based on the lowest Akaike Information Criterion (AIC) value.

The mean grain yield across trials for the selected lines and their characterized root and shoot trait observations were displayed on a MDPREF (multidimensional preference) biplot using SAS PROC PRINQUAL procedure (Caroll, 1972; Kuhfeld, 1992; Linting et al., 2007). MDPREF identifies the variability that is most salient to the preference patterns of the traits toward
Cambodia, respectively. In India the mean days to 50\% flowering ranged from 75 to 111 days, mean plant height from 81 to 117 $\mathrm{cm}$ and mean grain yield from 3.5 to $6.7 \mathrm{t} / \mathrm{ha}$, with heritability for grain yield 0.41 to 0.85 under AWD. In Nepal, the variability in genotypes under AWD ranged from 88 to 113 days for days to $50 \%$ flowering, 85 to $95 \mathrm{~cm}$ in term of mean plant height and 2.9 to $5.4 \mathrm{t} /$ ha for mean grain yield (Table 2). At Gazipur, Bangladesh the mean grain yield under AWD varied from 4.0 to $4.3 \mathrm{t} / \mathrm{ha}$ with estimated heritability ranging from moderate to high ( 0.61 to 0.98). At Phnom Penh, Cambodia the mean grain yield variability ranged from 3.4 to $3.8 \mathrm{t} / \mathrm{ha}$ and 3.6 to $4.1 \mathrm{t} / \mathrm{ha}$ under continuous flooding and AWD, respectively (Table 2 ).

\section{Potential Economic Investment}

Total water input across locations ranged from 782 to $1,705.4 \mathrm{~m}^{3}$. Total water input was higher during the wet season compared to the dry season. The total amount of water consumed in control (continuous flooding) and AWD treatment with total rainfall across seasons, years and locations is shown in Table 3. Water saving of 18.9 to $22.5,19.9,15.4,23.4,14.0 \%$, and 5.7 to $7.3 \%$ was observed at IRRI, India, Nepal, Bangladesh and Cambodia locations, respectively (Table 3 ).

\section{Mean Yield and Stability across Environments (Location $x$ Year)}

The mean grain yield of genotypes across environments ranged from 3.5 (IR14L255) to 5.6 t/ha (IR14L111, IR14L146, IR14L360, and IR11N313) (Supplementary Table 2). The mean yield of locations over years ranged from $3.7 \mathrm{t} / \mathrm{ha}$ (Cambodia; lower) to $6.6 \mathrm{t} / \mathrm{ha}$ (India; higher). A total of 33 genotypes had shown mean grain yield of more than $5.0 \mathrm{t} / \mathrm{ha}$ across locations. The mean grain 

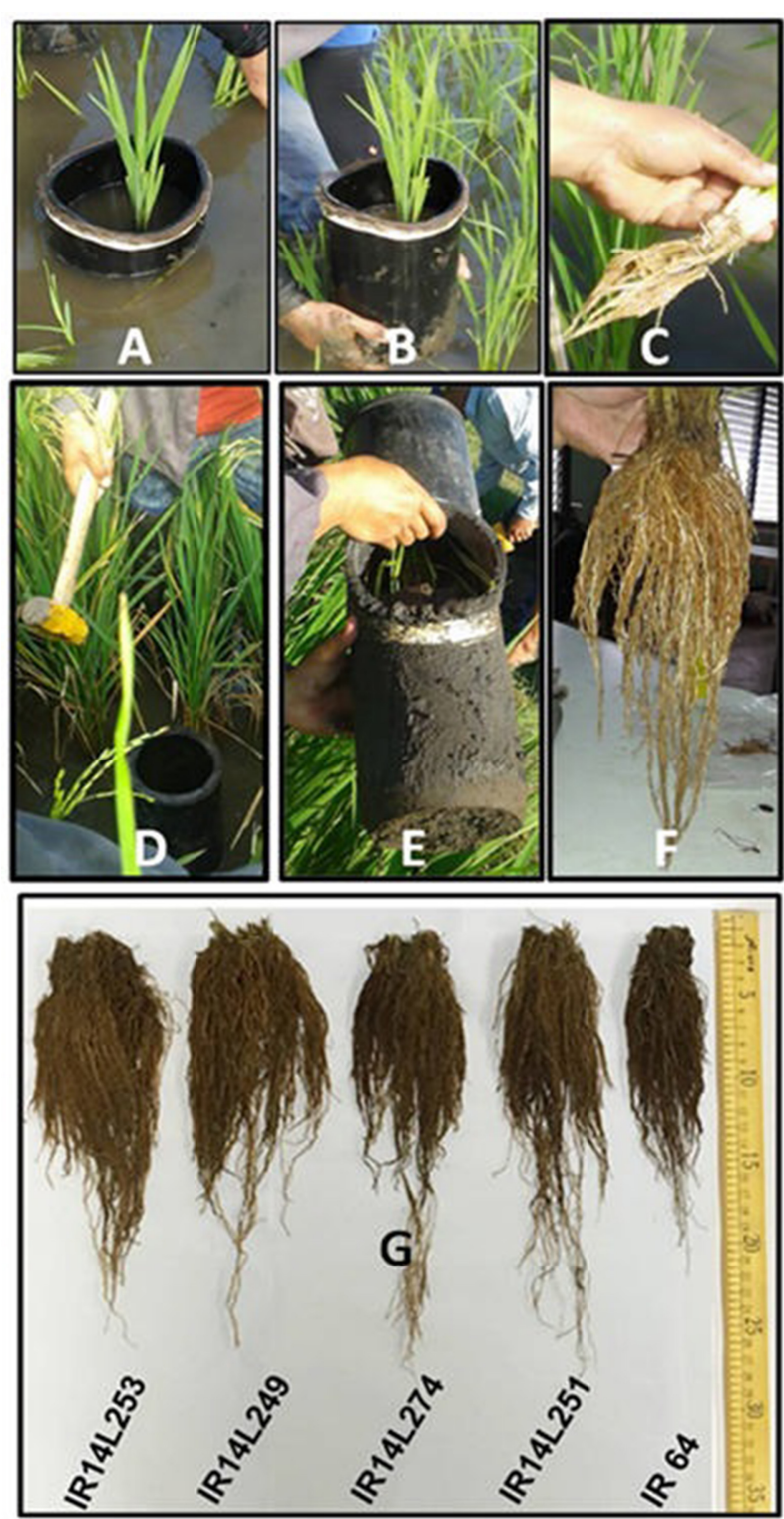

FIGURE 2 | (A-C) Root sampling at 15 days after transplanting in field. (D-F) Root sampling at $50 \%$ flowering. (G) Comparison of root system of selected lines and check (IR64) at flowering stage at IRRI, Philippines.

yield of 42 genotypes across environments varied from 4.0 to 5.0 $\mathrm{t} / \mathrm{ha}$. Most of the stable and high mean grain yielding genotypes across different locations and years/seasons was from rainfed lowland breeding program at IRRI (Supplementary Table 2), indicating the adaptability of lowland adapted genotypes across environments under AWD conditions.

Shukla stability variance model (homogeneous error variance) and Finlay-Wilkinson model (heterogeneous error) could meet the convergence criteria with the AIC values of 1,942.9 and 1,224.9, respectively. Therefore Finlay-Wilkinson model with lower AIC value was considered best suited to the data and the best performers for stability were identified.
Eighty two genotypes tested in three or more environments were used to evaluate yield stability of the genotypes across environments. Finlay-Wilkinson model (Finlay and Wilkinson, 1963) with heterogeneous variances for errors was the best fitting stability model. Genotypes IR14L249, IR14L157, IR14L135, IR11N313， IR14L253， IR11A282， IR14L273， IR14L158, IR12N135, and IR14L545 were good performers in terms of stability with regression coefficient approximating unity. Of these IR11N313, IR14L253, IR14L249, IR14L158, and IR14L157 were high yielding. Out of these, 8 genotypes (IR14L249, IRRI 123, IR14L273, IR14L251, IR14L253, IR11N313, IR14L545, IR11A334) had shown yield stability across locations with high mean grain yield performance (more than $5.0 \mathrm{t} / \mathrm{ha}$ ) (Table 4). It is important to highlight here that the three most stable and high mean grain yielding genotypes (IR14L253, IR14L249, and IR14L273) are the progenies of the crosses involving lowland adapted breeding genotypes-IR71700-247-1-1-2 and IR7018132-PMI 1-1-5-1, IRRI 163, respectively in their pedigree, indicating that these are potential donors in developing varieties suited to AWD.

The mean grain yield performance of genotype IR14L253, IR11N313 was estimated from 6 locations; IR14L273, IR14L249 from 5 locations and IR14L251, IR14L545, IR11A334 from 4 locations. The mean grain yield performance of selected genotypes across ecosystems (Philippines, India, Nepal, Bangladesh and Cambodia) is shown in Table 5. The stable yielding genotypes had shown grain yield advantage of 9.1 to $30.9 \%, 28.6$ to $55.1 \%$ and 6.9 to $51.7 \%$ over locally adapted check (IR64) in Philippines, India and Nepal, respectively. The percentage increase in grain yield of selected stable genotypes over the locally adapted check BRRI dhan 28 in Bangladesh ranged from 2.0 to $32.7 \%$, and over locally adapted check Chul'sa in Cambodia ranged from 12.8 to $25.6 \%$. The selected genotypes had shown low chalkiness, medium amylose content and high head rice recovery (Table 5), indicating their suitability to be released as a variety for cultivation under AWD system.

Regression coefficient value of a particular genotype across environments provides an estimate about the adaptability of genotype toward different environments and locations and help breeders to select the genotypes. A total of 49 genotypes had shown regression coefficient value (rescaled beta) decreasing below unity (1), out of which 5 genotypes had grain yield less than $4.0 \mathrm{t} /$ ha while 19 genotypes yielded more than $5.0 \mathrm{t} / \mathrm{ha}$ across locations, indicating high yield performance of 19 genotypes with higher adaptation to environmental change (rescaled beta $>1$ ) (Supplementary Table 2). On other hand 30 genotypes had shown regression coefficient value increasing above unity, out of which 3 genotypes yielded less than $4.5 \mathrm{t} / \mathrm{ha}$ and remaining 13 yielded more than $5.0 \mathrm{t} / \mathrm{ha}$ across locations, indicating better overall yield performance of 13 genotypes with sensitivity to environmental change (Supplementary Table 2).

\section{Evaluation of Root Traits}

The genotypes based on their stable yield performance under AWD and continuous flooding control conditions were selected and screened for root traits at IRRI. Grain yield data for 27 genotypes screened at IRRI across seasons (common 
TABLE 2 | Descriptive agronomic traits statistics under different treatments and across ecosystems with experimental details.

\begin{tabular}{|c|c|c|c|c|c|c|c|c|c|c|}
\hline Exp & Location & Year/season & Trt & Experimental design & No. of rep & No. of entries & \multicolumn{3}{|c|}{ Trial mean } & $\begin{array}{c}\text { Trial H } \\
\text { GY }\end{array}$ \\
\hline 2 & & 2015DS & AWD & $(10 \times 7) \mathrm{AL}$ & 3 & 70 & 86 & 95 & 6.5 & 0.75 \\
\hline 3 & & 2015DS & AWD & $(10 \times 13) \mathrm{AL}$ & 2 & 130 & 88 & 107 & 7.2 & 0.79 \\
\hline 4 & & 2015WS & NS & $(8 \times 11) \mathrm{AL}$ & 2 & 88 & 88 & 120 & 5.3 & 0.82 \\
\hline 6 & & 2015WS & AWD & $(8 \times 8) \mathrm{AL}$ & 2 & 64 & 89 & 121 & 4.8 & 0.81 \\
\hline 7 & & 2016DS & AWD & $\mathrm{RCBD}$ & 2 & 28 & 79 & 105 & 7.5 & 0.64 \\
\hline 8 & & 2016WS & AWD & $\mathrm{RCBD}$ & 2 & 11 & 82 & 117 & 5.1 & 0.92 \\
\hline 9 & Hyderabad, India & 2015WS & AWD & $(3 \times 60)$ augmented RCBD & - & 60 & 75 & 100 & 6.7 & 0.85 \\
\hline 10 & & 2016DS & AWD & $(3 \times 10) A L$ & 2 & 30 & 97 & 87 & 5.8 & 0.41 \\
\hline 11 & & 2016DS & AWD & $(3 \times 50)$ augmented RCBD & - & 50 & 111 & 81 & 3.5 & 0.42 \\
\hline 15 & & 2016DS & AWD & $\mathrm{RCBD}$ & 2 & 38 & 97 & 92 & 5.4 & 0.96 \\
\hline 16 & RARS, Tarahara & 2015WS & AWD & $(39 \times 5) \mathrm{AL}$ & 2 & 195 & 113 & 85 & 2.9 & 0.65 \\
\hline 17 & & 2016DS & AWD & $(12 \times 3) A L$ & 2 & 36 & 88 & 92 & 4.0 & 0.74 \\
\hline 18 & Gazipur, Bangladesh & 2015WS & AWD & $(12 \times 5) \mathrm{AL}$ & 2 & 60 & 99 & 98 & 4.3 & 0.98 \\
\hline 19 & & 2016DS & AWD & $(3 \times 42)$ augmented RCBD & - & 42 & 111 & 95 & 4.0 & 0.61 \\
\hline 20 & Phnom Penh, Cambodia & 2016DS & NS & $(2 \times 60)$ augmented RCBD & - & 60 & 80 & 106 & 3.4 & 0.94 \\
\hline 21 & & 2016DS & AWD & $(2 \times 60)$ augmented RCBD & - & 60 & 80 & 106 & 3.6 & 0.98 \\
\hline 22 & & 2016DS & NS & RCBD & 2 & 39 & 78 & 89 & 3.8 & 0.79 \\
\hline 23 & & 2016DS & AWD & $\mathrm{RCBD}$ & 2 & 39 & 106 & 110 & 4.1 & 0.71 \\
\hline
\end{tabular}

DS, dry season; WS, wet season; NS, control continuous flooding; AWD, alternate wetting and drying; AL, alpha lattice; RCBD, randomized complete block design; rep, replications; DTF, days to $50 \%$ flowering (days); $P H T$, plant height (cm); GY, grain yield (t/ha); $H$, heritability.

in 2015DS and 2015WS) under continuous flooding and AWD conditions were subjected to analysis of variance. Four genotypes, which showed non-significant yield differences under AWD and continuous flooding control conditions, were selected for root studies in 2016WS under AWD conditions (Table 6).

The root traits, nodal root number and root dry weight at $10-20 \mathrm{~cm}$ depth on $22-30$ DAT and percentage increase in these root traits after initiation of AWD cycle play an important role in maintaining grain yield under AWD in the selected genotypes. The lowland adapted check (IR64) had shown significant grain yield difference with lower yield under AWD conditions compared to continuous flooding control conditions (Table 6). The nodal root number in IR64 was higher compared to the selected genotypes before the initiation of the AWD treatment (15 days after transplanting [DAT]). After the initiation of the treatment, at 22 and 30 DAT, all the four selected genotypes maintained more nodal roots and higher root dry weight compared to lowland adapted check (IR64) (Table 7) between 10 and $20 \mathrm{~cm}$. Percent increase in nodal root number, root length and root dry weight at 22 DAT, 30 DAT and days to $50 \%$ flowering was higher in the selected genotypes compared to IR64 (Table 8). Number of nodal root below $20 \mathrm{~cm}$ showed significant difference at flowering stage (50\% flowering, Table 7). The percent increase in nodal root number and root dry weight from 15 DAT to 22, 15 to 30 DAT, from 15, 22, and 30 DAT to days to $50 \%$ flowering were significantly higher in the selected genotypes compared to IR64 (Table 8).

\section{Relationships among Traits and Genotypes}

The relationship among the selected genotypes and traits (seedling establishment, root, shoots and grain yield) were examined using multi-dimensional preference analysis (MDPREF) biplots. A trait vector in direction of particular set of genotypes signified the most preferred trait for those genotypes. In each biplot, most of the variability is covered by the first two preference axes and the trait scores are joined to the origin by the trait vectors. The projection of genotype on the trait vector corresponds to the relationship of genotype with the trait. Separate biplots were drawn for root traits vs. grain yield (Figure 3A), seedling establishment (relative growth rate) and shoot dry weight vs. grain yield (Figure 3B) and root, seedling establishment and shoot dry weight vs. grain yield (Figure 3C). The biplots involving different combination of traits showed clearly interpretable dimensions that underlie the data.

The traits at 22 and 30 DAT; root traits such as nodal root number at 15 DAT (NRA), nodal root number at 22 DAT (NRB), nodal root number at $30 \mathrm{DAT}$ (NRC), root dry weight at $22 \mathrm{DAT}$ (RDWB), root dry weight at 30 DAT (RDWC), root length at 
TABLE 3 | Economic water saving under AWD compared to continuous flooding (control) across different ecosystems.

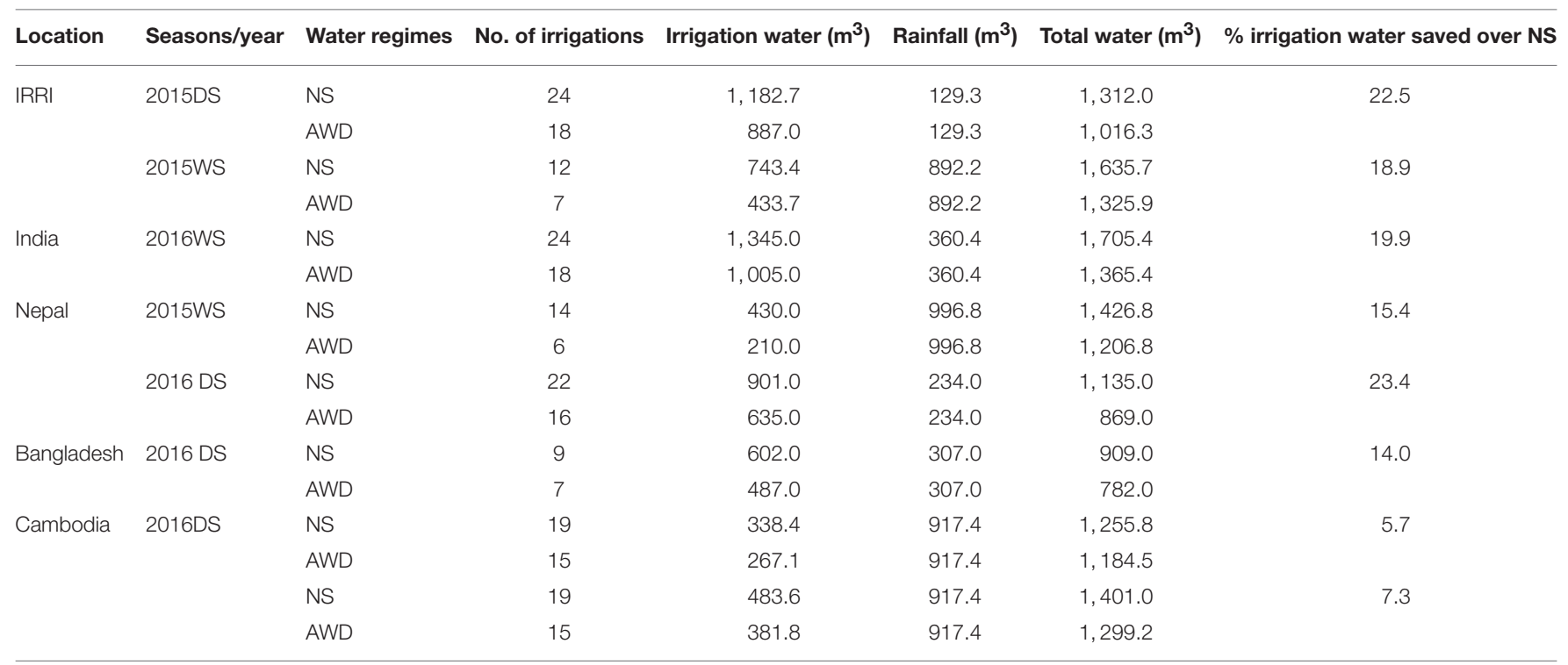

DS, dry season; WS, wet season; NS, control continuous flooding; AWD, alternate wetting and drying; $m^{3}$, cubic meter.

TABLE 4 | Grain yield stability of selected genotypes across ecosystems based on the best fitting (Finlay-Wilkinson regression model) variance-covariance structure according to the Akaike Information Criterion (AIC).

\begin{tabular}{|c|c|c|c|c|c|c|}
\hline Designation & Estimate & Standard error & Z-value & $\operatorname{Pr} Z$ & Rescaled beta & Mean grain yield ( $\mathrm{t} / \mathrm{ha}$ ) across locations \\
\hline IR11A334 & 1.6405 & 0.4426 & 3.71 & 0.0002 & 1.04 & 5.2 \\
\hline IR11N313 & 1.5662 & 0.3280 & 4.78 & $<0.0001$ & 0.99 & 5.6 \\
\hline IR14L249 & 1.5759 & 0.3298 & 4.78 & $<0.0001$ & 1.00 & 5.4 \\
\hline IR14L251 & 1.6804 & 0.3529 & 4.78 & $<0.0001$ & 1.07 & 5.2 \\
\hline IR14L253 & 1.5598 & 0.3263 & 4.78 & $<0.0001$ & 0.99 & 5.5 \\
\hline IR14L273 & 1.5486 & 0.3486 & 4.44 & $<0.0001$ & 0.98 & 5.3 \\
\hline IR14L545 & 1.6394 & 0.3631 & 4.52 & $<0.0001$ & 1.04 & 5.3 \\
\hline |RR| 123 & 1.5128 & 0.3172 & 4.77 & $<0.0001$ & 0.96 & 5.3 \\
\hline IR64 & 2.1486 & 0.5971 & 3.60 & 0.0003 & 1.36 & 4.5 \\
\hline
\end{tabular}

AlC for the model: 1224.9.

22 DAT (RLB), root length at 30 DAT (RLC); shoot traits such as shoot dry weight at 22 DAT (SDWB), shoot dry weight at 30 DAT (SDWC); seedling establishment traits such as relative growth rate from 22 to 15 DAT (RGRA) and relative growth rate from 30 to 15 DAT (RGRC) grouped together (Figure 3). The vectors corresponding to RDW at 22 and 30 DAT; NR at 15,22 , and 30 DAT grouped together with grain yield (GY) (Group-A) were positioned closely on the top right space while the vectors corresponding to RL at 22 and $30 \mathrm{DAT}$ ); and nodal root number at days to $50 \%$ flowering (NRD) (Group-B) that formed another group were located toward the center on the right (Figure 3A). The vectors corresponding to root length at 15 DAT (RLA) and root length at days to $50 \%$ flowering (RLD); root dry weight at 15 DAT (RDWA) and root dry weight at days to 50\% flowering (RDWD); and (nodal root number below $20 \mathrm{~cm}$ (NRE) (Group-C) tended toward the bottom right space (Figure 3A). Genotypes 3, 2, and 4 were the best performers for the Group-A, B, and C set of traits, respectively. Genotypes 1 and 5 located at the origin were mostly non-responsive (Figure 3A).

For the biplot for shoot and seedling establishment traits with GY, the vector corresponding to SDW at 22DAT, and $30 \mathrm{DAT}$; RGR from 22 to 15 DAT grouped together with GY (Group-A) were positioned closely toward the center on right whereas other traits were further apart (Figure 3B). Genotypes 2 (IR14L251) and 3 (IR14L253) were the best performers for the Group-A (Figure 3B).

The relationship among traits (seedling establishment, root, shoot and grain yield) and the selected genotypes across the growth period (seedling to maturity) was investigated. The vector corresponding to root traits (NR, RL, and RDW), shoot traits (SDW) at 22 DAT and 30 DAT; seedling establishment traits (RGR from 22 to 15 DAT and from 30 to 15 DAT) grouped together with GY (Group-B). The other measured traits grouped 
TABLE 5 | Mean grain yield (t/ha) performance and grain quality parameters of selected genotypes across ecosystems.

\begin{tabular}{|c|c|c|c|c|c|c|c|c|}
\hline Designation & Philippines & India & Nepal & Bangladesh & Cambodia & Chalkiness & Amylose content & $\%$ Head_Rice \\
\hline IR11A334 & 6.0 & 6.3 & 4.3 & 6.5 & - & 7.2 & 22.4 & 49.0 \\
\hline IR11N313 & 6.9 & 7.5 & 4.4 & 5.0 & 4.4 & 3.5 & 20.7 & 49.2 \\
\hline IR14L249 & 6.7 & 7.6 & 3.1 & 4.9 & - & 3.3 & 24.7 & 59.2 \\
\hline IR14L251 & 6.9 & 7.0 & 3.2 & 4.6 & - & 8.7 & 25.6 & 52.8 \\
\hline IR14L253 & 7.2 & 6.4 & 4.4 & 4.4 & 4.9 & 10.0 & 23.0 & 43.9 \\
\hline |RRI 123 & 6.4 & - & 3.3 & - & - & 14.0 & 22.0 & 48.9 \\
\hline IR64 & 5.5 & 4.9 & 2.9 & - & - & 11 & 21.8 & 47.6 \\
\hline BRRI dhan 28 & - & - & - & 4.9 & - & & & \\
\hline BRRI dhan 56 & - & - & - & 4.8 & - & & & \\
\hline Chul'sa & - & - & - & - & 3.9 & & & \\
\hline
\end{tabular}

LSD, least significance difference (5\%); CV (\%), coefficient of variance; $H$, heritability.

TABLE 6 | Comparison of grain yield (t/ha) of selected lines under AWD and continuous flooding (control) conditions at IRRI, Philippines.

\begin{tabular}{|c|c|c|c|c|c|c|c|c|c|c|}
\hline Designation & 2015DS_NS & 2015DS_AWD & Std error of diff & $F$-value & 2015WS_NS & 2015WS_AWD & Std error of diff & $F$-value & 2016DS_AWD & 2016WS_AWD \\
\hline IR14L249 & 7.4 & $6.5^{\mathrm{ns}}$ & 0.584 & 2.42 & 5.9 & $5.7^{\mathrm{ns}}$ & 0.335 & 0.04 & 8 & 4.9 \\
\hline IR14L251 & 7.1 & $7.0^{\mathrm{ns}}$ & 0.853 & 0.03 & 5.6 & $5.9^{\text {ns }}$ & 0.824 & 0.18 & 7.8 & 5.3 \\
\hline IR14L253 & 7.8 & $7.8^{\mathrm{ns}}$ & 0.189 & 0.25 & 6.4 & $5.7^{\mathrm{ns}}$ & 0.197 & 7.96 & 8.3 & 6 \\
\hline IR14L274 & 8.2 & $6.6^{\mathrm{ns}}$ & 1.6 & 0.67 & 5.7 & $6.0^{\text {ns }}$ & 0.45 & 0.58 & 7.7 & 4.6 \\
\hline IR64 & 6.6 & $5.8^{\star}$ & 0.099 & 358.7 & 5.9 & $4.8^{\star}$ & 0.054 & 430.97 & 7.4 & 5.2 \\
\hline Trial mean & 7.4 & 6.5 & 0.704 & 2.82 & 5.3 & 5.7 & 0.563 & 3.4 & 7.5 & 5.1 \\
\hline LSD (5\%) & 1.9 & 0.91 & - & - & 1.11 & 9.9 & - & - & 0.8 & 0.87 \\
\hline CV (\%) & 11.9 & 7.9 & - & - & 1.14 & 9.7 & - & - & 5.4 & 6.2 \\
\hline
\end{tabular}

ns, genotype had no significance difference in yield under NS and AWD conditions across rows.

*Significant difference at 0.05.

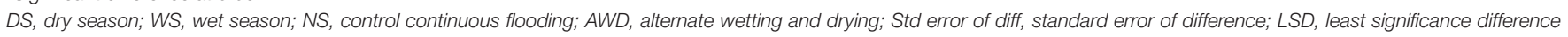
(5\%); CV (\%), coefficient of variance.

together in Group-A except seedling establishment traits (RGR from 30 to $22 \mathrm{DAT}$ and from days to $50 \%$ flowering to $15 \mathrm{DAT}$ ); and shoot trait (SDW at days to $50 \%$ flowering) (Figure 3C). Genotypes 2 and 3 were the best performers for the Group-B (Figure 3C).

\section{DISCUSSION}

Better crop establishment, high and stable yield, and phenotypic plasticity to adapt across variable growing conditions are the most important reasons for implementing the watersaving investment technologies that will result in a more sustainable agriculture. In the present study, large variability in agronomic traits including grain yield under AWD conditions at different locations, seasons and years resulted from different soil types, characteristics, textures and water holding capacity; soil nutrient dynamics; nutrient cycle; crop fertility maintenance and changing climate (Bouman and Tuong, 2001; Mandal et al.,
2009; Price et al., 2013). The economic impact of AWD on saving water (5.7-23.4\%) depending on season, without significant yield penalty across different topological ecosystems indicates the potential of technology to address the major challenge of water scarcity in irrigated ecosystems. AWD system of irrigation significantly reduces the water use (by 30\%, Bouman et al., 2007, 21-56\%, Nalley et al., 2015, 23\%, Carrijo et al., 2017; 57\% Howell et al., 2015) while maintaining (Howell et al., 2015) or even increasing yields, compared to the traditional continuous flooding system (Mishra et al., 1990; Bouman and Tuong, 2001; Tabbal et al., 2002; Belder et al., 2004; Mandal et al., 2009; Mishra and Salokhe, 2010).

The yield stability and high mean grain yield potential of genotype across variable growing conditions and ecosystems indicate their potential in maintaining proper balance, trade-off and partitioning between root-shoot system. The genotypes with regression coefficient value increasing above 1.0 (Supplementary Table 2) possessed high sensitivity to 


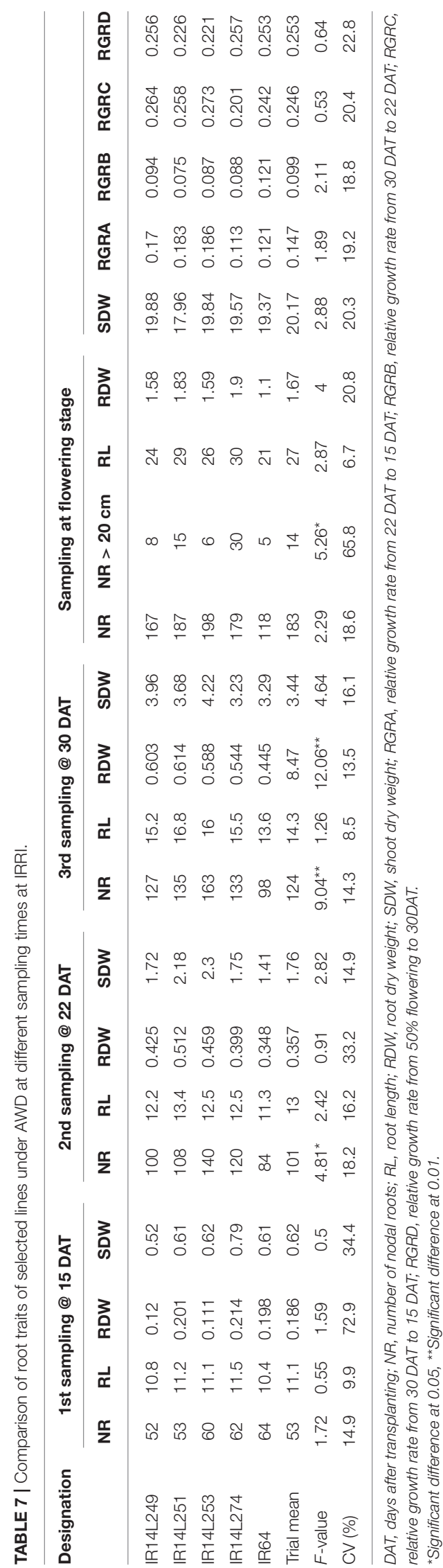

environmental change, (thus below average stability) and adaptability to favorable environments. Regression coefficient value decreasing below 1.0 (Supplementary Table 2) provides a measure of greater adaptation to environmental change, (thus above average stability) and increasing adaptability to unfavorable environments. This may provide useful information during selection of genotypes with a high mean grain yield and adaptability for specific location. Identification of rice genotypes with high, stable yield under AWD across ecosystems and without any yield penalty under continuous flooding conditions shall promote the adoption and dissemination of water saving AWD technology among farmers. The better grain quality parameters of the selected genotypes indicate the potential of the genotypes to be released as varieties.

The modification of root system architecture of presently cultivated rice genotypes or the identification of stable high yielding genotypes with plasticity in their root systems with change in ecosystems may increase the chances of improving water savings as well as yield under AWD. The adaptive behavior of the root systems of currently available irrigated system genotypes relative to the timing and severity of fluctuating water-nutrient availability is a critical issue in optimizing AWD technology. It is hypothesized that different rice genotypes with comparatively more nodal roots and higher root dry weight in the $15-20 \mathrm{~cm}$ root zone are expected to perform better under AWD compared to genotypes with fewer nodal roots within $15-20 \mathrm{~cm}$ depth. The fluctuating wetting and drying spells during AWD can improve nutrient cycling processes, microbial dynamics and nutrient mineralization by disrupting the soil aggregates and provoking both physical and biological changes to optimize resource use efficiency to benefit the plant. During AWD treatment, since the water table goes below a depth of 15 $\mathrm{cm}, 1$ or 2 days of delay in irrigation can sometimes reduce the nutrient availability along with the water. In the present study, we measured a number of root traits such nodal root number, nodal root number below $20 \mathrm{~cm}$, root length, root dry weight, root hair length, and root hair density (data not reported) at 15,22 , and $30 \mathrm{DAT}$ and days to $50 \%$ flowering. However, only nodal roots and root dry weight showed significant differences. More nodal roots between 0 and $15 \mathrm{~cm}$ upto 22 DAT and between 0 and $20 \mathrm{~cm}$ thereafter helps breeding lines to have better nutrient uptake, therefore counter the yield reduction under AWD compared to genotypes with lesser nodal root number. The present study underlines importance of presence of higher number of nodal roots and a higher root dry weight between 10 and $20 \mathrm{~cm}$ at 22 to 30 DAT in test genotypes producing higher yield under AWD compared to the check IR64. This validates our hypothesis and signifies the suitability of the identified root traits in providing better adaptation under AWD. In our present root study we have also used upland adapted control such as Kali Aus and Aus 276. However, as AWD is transplanted lowland water saving practice and IR64 is a popular, widely grown, high yielding mega rice variety for lowland irrigated system with the similar growth duration as that of genotypes under study, we made comparisons for root traits as well as yield with IR64. Like any other upland genotype, Kali Aus and Aus 276 have well developed root system and 
TABLE 8 | Percent increase in different root traits of selected lines at 22 and 30 DAT and days to 50\% flowering under AWD condition at IRRI.

\begin{tabular}{|c|c|c|c|c|c|c|c|c|c|c|c|c|}
\hline \multirow[t]{2}{*}{ Designation } & \multicolumn{2}{|c|}{$\begin{array}{l}\% \text { increase from } 15 \\
\text { DAT to } 22 \text { DAT }\end{array}$} & \multicolumn{2}{|c|}{$\begin{array}{l}\% \text { increase from } 22 \\
\text { DAT to } 30 \text { DAT }\end{array}$} & \multicolumn{2}{|c|}{$\begin{array}{c}\% \text { increase from } 30 \\
\text { DAT to days to } 50 \% \\
\text { flowering }\end{array}$} & \multicolumn{2}{|c|}{$\begin{array}{l}\% \text { increase from } 15 \\
\text { DAT to } 30 \text { DAT }\end{array}$} & \multicolumn{2}{|c|}{$\begin{array}{c}\% \text { increase from } 22 \\
\text { DAT to days to } 50 \% \\
\text { flowering }\end{array}$} & \multicolumn{2}{|c|}{$\begin{array}{c}\% \text { increase from } 15 \\
\text { DAT to days to } 50 \% \\
\text { flowering }\end{array}$} \\
\hline & NR & RDW & NR & RDW & NR & RDW & NR & RDW & NR & RDW & NR & RDW \\
\hline IR14L249 & 92.1 & 256.1 & 27.8 & 42.3 & 31.1 & 161.7 & 145.5 & 401.8 & 67.6 & 270.9 & 221.9 & $1,218.9$ \\
\hline IR14L251 & 104.1 & 157.5 & 24.3 & 20.5 & 39.2 & 196.6 & 153.6 & 213.1 & 72.9 & 310.8 & 252.7 & 842.6 \\
\hline IR64 & 50.2 & 61.2 & 16.9 & 48.9 & 20.2 & 86.4 & 57.1 & 112.1 & 40.5 & 165.9 & 89.1 & 486.7 \\
\hline Trial mean & 108.9 & 164.96 & 20.01 & 36.17 & 34.60 & 181.38 & 147.38 & 236.30 & 55.52 & 272.94 & 217.23 & $1,193.24$ \\
\hline LSD & 41.54 & 111.0 & 23.50 & 68.50 & 10.78 & 75.08 & 47.90 & 108.44 & 16.76 & 93.12 & 93.18 & 2,596 \\
\hline$F$-value & $13.34^{\star *}$ & $5.32^{*}$ & 0.6442 & 0.194 & $7.11^{\star}$ & $5.35^{*}$ & $10.89^{* \star}$ & $8.05^{\star}$ & $5.54^{\star}$ & $5.51^{*}$ & $6.44^{*}$ & 0.7932 \\
\hline CV (\%) & 19.07 & 27.71 & 18.57 & 29.94 & 15.59 & 20.70 & 16.25 & 22.95 & 15.09 & 17.06 & 21.45 & 34.42 \\
\hline
\end{tabular}

DAT, days after transplanting; NR, number of nodal roots; RL, root length; RDW, root dry weight; SDW, shoot dry weight; LSD, least significance difference (5\%); CV (\%), coefficient of variance.

${ }^{*}$ Significant difference at $0.05,{ }^{*}$ Significant difference at 0.01

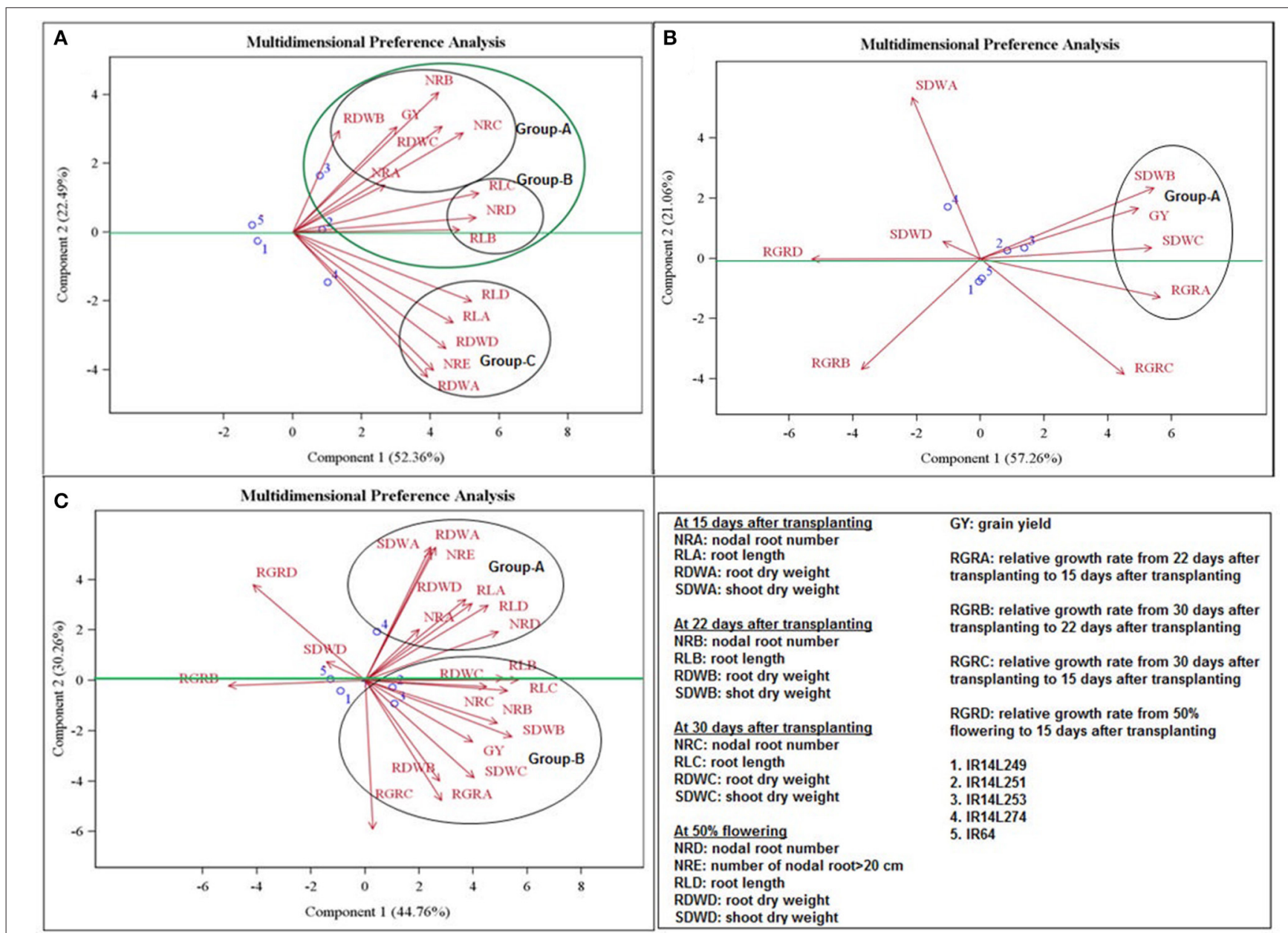

FIGURE 3 | Multidimensional preference analysis biplot of (A) root traits with grain yield; (B) seedling establishment and shoot traits with grain yield; (C) seedling establishment, root and shoot traits with grain yield. 
comparison of root traits of lowland adapted genotype with upland adapted genotypes would not have been proper. At flowering stage, number of nodal root below $20 \mathrm{~cm}$ and deep root length appears to have an effect on yield. The percent increase in nodal root number and root dry weight from 15 to 22 DAT and thereafter 30 DAT to 50\% flowering (Table 8) has major role to play in water-nutrient uptake under AWD and decreasing grain yield reduction. The study highlights the significance of percent increase in root traits after initiation of the AWD cycle till 50\% flowering, grouping of root with grain yield and the responsiveness of genotype possessing such traits to provide high and stable yield across different ecosystems. These novel findings shall encourage plant breeders for the application of the identified traits in the development of better rice cultivars for AWD condition. The soil aerating practice (Thakur et al., 2011) and high root dry weight (Pascual and Wang, 2017) implies more uptake of water and nutrients (Ndiiri et al., 2012) from the soil through to the root system (Dobermann and Fairhurst, 2000; Kirk, 2004) and better remobilization of carbohydrates from the source (stems) to the sink (grain) characterize the key method of enhancing grain filling under AWD conditions (Yang and Zhang, 2010).

\section{CONCLUSIONS}

AWD system of rice cultivation has huge potential to save water and increase crop productivity but has not become popular because currently available rice varieties showed yield reduction under AWD. The study identified the contribution of nodal roots and root dry weight at $10-20 \mathrm{~cm}$ depth on 22-30 DAT in preventing yield reduction under AWD compared to flooded irrigation system. The findings shall encourage plant breeders to apply selection for these two traits in the development of rice cultivars for AWD condition. Identification of novel rice genotypes with high, stable yield under AWD across ecosystems shall help disseminate and popularize AWD system among farmers and achieve on average $20 \%$ water saving in rice cultivation without any yield reduction.

\section{REFERENCES}

Belder, P., Bouman, B. A. M., Cabangon, R., Lu, G., Quilang, E. J. P., Li, Y., et al. (2004). Effect of water saving irrigation on rice yield and water use in typical lowland conditions in Asia. Agric. Water Manage. 65, 193-210. doi: 10.1016/j.agwat.2003.09.002

Bhuiyan, S. I. (1992). Water management in relation to crop production, case study on rice. Outlook Agric. 21, 293-299. doi: 10.1177/003072709202100408

Bouman, B. A. M., Lampayan, R. M., and Tuong, T. P. (2007). Water Management in Rice: Coping with Water Scarcity. Los Baños: International Rice Research Institute.

Bouman, B. A. M., and Tuong, T. P. (2001). Field water management to save water and increase its productivity in irrigated rice Agric. Water Manage. 49, 11-30. doi: 10.1016/S0378-3774(00)00128-1

Caroll, J. D. (1972). "Individual preferences and multi-dimensional scaling," in Multi-Dimensional Scaling Theory and Applications in the Behavioural Sciences, Vol. 1, eds R. N. Shepard, A. K. Romney, and S. Nerlove (New York, NY; London: Seminar Press), 105-155.

\section{AVAILABILITY OF DATA AND MATERIALS}

The data sets supporting the results of this article are included within the article.

\section{AUTHOR CONTRIBUTIONS}

NS was involved in conducting the experiment, analysis, data interpretation, and drafting of the manuscript; SS, VL, BCo, PP, $\mathrm{PM}$, and $\mathrm{MC}$ were involved in conducting the experiment at IRRI; RY and $\mathrm{BCh}$ were involved in conducting the experiment at NRRP, Hardinath (Nepal); HP was involved in conducting the experiment at RARS, Tarahara (Nepal); KI was involved in conducting the experiment at BRRI, (Bangladesh); KB and MR were involved in conducting the experiment at RRS, Kaul (India); $\mathrm{CV}$ was involved in conducting the experiment at Hyderabad (India); TT and VT were involved in conducting the experiment at Phnom Penh (Cambodia); KR was involved in data analysis; AK conceived the study and was involved in critical revision of the manuscript and final approval of the version to be published.

\section{ACKNOWLEDGMENTS}

We thank the Asian Development Bank and the Government of Finland for financial support to this study through the project "TA8441-Development and dissemination of climate resilient rice varieties for water short areas of South Asia and Southeast Asia."

\section{SUPPLEMENTARY MATERIAL}

The Supplementary Material for this article can be found online at: https://www.frontiersin.org/articles/10.3389/fpls.2017. 01879/full\#supplementary-material

Supplementary Figure 1 | AWD pipes and system for scheduling irrigation: (A) when water table level is at the level of surface; (B) when water table level is $>10$ $\mathrm{cm}$; (C) when water table level is $>15 \mathrm{~cm}$.

Supplementary Figure 2 | Water table level in 2016WS averaged from three AWD pipe installed in zig-zag manner in field.

Carrijo, D. R., Lundy, M. E., and Linquist, B. A. (2017). Rice yields and water use under alternate wetting and drying irrigation: a meta-analysis. Field Crops Res. 203, 173-180. doi: 10.1016/j.fcr.2016.12.002

Cherif, M., Audebert, A., Fofana, M., and Zouzou, M. (2009). Evaluation of iron toxicity on lowland irrigated rice in West Africa. Tropicultura 27, 88-92.

Davies, W., Zhang, J. J., Yang, J., and Dodd, I. C. (2011). Novel crop science to improve yield and resource use efficiency in water- limited agriculture. $J$. Agricult. Sci. 149, 123-131. doi: 10.1017/S0021859610001115

Dobermann, A., and Fairhurst, T. (2000). Rice, Nutrient Disorders and Nutrient Management. Los Banos, CA; Manila: Potash and Phosphate Institute, Singapore and International Rice Research Institute.

FAO (2016). FAOSTAT Database. Rome: Food and Agriculture Organization of the United Nations.

Finlay, K. W., and Wilkinson, G. N. (1963). The analysis of adaptation in a plant-breeding programme. Aust. J. Agric. Res. 14, 742-754. doi: 10.1071/AR96 30742

Howell, K. R., Shrestha, P., and Dodd, I. C. (2015). Alternate wetting and drying irrigation maintained rice yields despite half the irrigation volume, but is 
currently unlikely to be adopted by smallholder lowland rice farmers in Nepal. Food Energy Security 4, 144-157. doi: 10.1002/fes3.58

IRRI (2009). Every drop counts. Rice Today 8, 16-19.

Kirk, G. J. D. (2004). The Biogeochemistry of Submerged Soils. Chichester: Wiley. doi: 10.1002/047086303X

Kuhfeld, W. F. (1992). "Marketing research, uncovering competitive advantages," in Proceeding of the SAS Users Group International Conference (Kansas City, MO).

Li, C., Salas, W., DeAngelo, B., and Rose, S. (2006). Assessing alternatives for mitigating net greenhouse gas emissions and increasing yields from rice production in China over the next twenty years. J. Environ. Qual. 35, 1554-1565. doi: 10.2134/jeq2005.0208

Linting, M., Meulman, J. J., Groenen, P. J., and van der, Kooij, A. J. (2007). Nonlinear principal components analysis, introduction and application. Psychol. Methods 12, 336-358. doi: 10.1037/1082-989X.12.3.336

Littell, R. C., Milliken, G. A., Stroup, W. W., Wolfinger, R. D., and Schabenberger, O. (2006). SAS for Mixed Models, 2nd Edn. Cary, NC: SAS Institute Inc.

Mandal, S. N., Regmi, A., Ladha, J., and Tuong, T. (2009). "Crop establishment tillage and water management effects on crop and water productivity in the rice-wheat rotation in Nepal," in Integrated Crop and Resource Management in the Rice-Wheat System of South Asia, eds J. K. Ladha, Y. Singh, O. Erenstein, and B. Hardy (Los Baños: International Rice Research Institute), 239-260.

Mishra, A., and Salokhe, V. M. (2010). The effects of planting pattern and water regime on root morphology physiology and grain yield of rice. J. Agron. Crop Sci. 196, 368-378. doi: 10.1111/j.1439-037X.2010.00421.x

Mishra, H. S., Rathore, T. R., and Pant, R. C. (1990). Effect of intermittent irrigation on groundwater table contribution irrigation requirement and yield of rice in Mollisols of the Tarai region. Agric. Water Manag. 18, 231-241. doi: 10.1016/0378-3774(90)90045-Z

Moya, P., Hong, L., Dawe, D., and Chongde, C. (2004). The impact of on- farm water saving irrigation techniques on rice productivity and profi tability in Zhanghe Irrigation System Hubei China. Paddy Water Environ. 2, 207-215. doi: 10.1007/s10333-004-0063-2

Nalley, L., Linquist, B., Kovacs, K., and Anders, M. (2015). The economic viability of alternative wetting and drying irrigation in Arkansas rice production. Agron. J. 107, 579-587. doi: 10.2134/agronj14.0468

Ndiiri, J. A., Mati, B. M., Home, P. G., Odongo, B., and Uphoff, N. (2012). Comparison of water saving of paddy rice under system of rice intensification (SRI) growing in Mwea, Kenya. Int. J. Curr. Res. Rev. 4, 62-73.

Pascual, V. J., and Wang, Y. M. (2017). Utilizing rainfall and alternate wetting and drying irrigation for high water productivity in irrigated lowland paddy rice in southern Taiwan. Plant Prod. Sci. 20, 24-35. doi: 10.1080/1343943X.2016.1242373

Piepho, H. P. (1999). Stability analysis using the SAS system. Agron. J. 9, 154-160. doi: 10.2134/agronj1999.00021962009100010024x

Price, A. H., Norton, G. J., Salt, D. E., Ebenhoeh, O., Meharg, A. A., and Meharg, C. (2013). Alternate wetting and drying irrigation for rice in Bangladesh, Is it sustainable and has plant breeding something to offer? Food Energy Sec. 2, 120-129. doi: $10.1002 /$ fes 3.29

Sarkar, S. (2001). Effect of water stress on growth productivity and water expense efficiency of summer rice. Indian J. Agril. Sci. 71, 153-158.

Singh, S., Sharma, S. N., and Prasad, R. (2001). The effect of seeding and tillage methods on productivity of rice-wheat cropping system. Soil Til. Res. 61, 125-131. doi: 10.1016/S0167-1987(00)00188-4

Singh, U. M., Yadav, S., Dixit, S., Ramayya, P. J., Devi, M. N., Raman, K. A., et al. (2017). QTL hotspots for early vigor and related traits under dry direct-seeded system in rice (Oryza sativa L.). Front. Plant Sci. 8:286. doi: 10.3389/fpls.2017.00286

Tabbal, D. F., Bouman, B. A. M., Bhuiyan, S. I., Sibayan, E. B., and Sattar, M. A. (2002). On-farm strategies for reducing water input in irrigated rice, case studies in the Philippines. Agric. Water Manage. 56, 93-112. doi: $10.1016 /$ S0378-3774(02)00007-0
Thakur, A. K., Rath, S., Patil, D. U., and Kumar, A. (2011). Effects on rice plant morphology and physiology of water and associated management practices of system of rice intensification and their implications for crop performance. Paddy Water Environ. 9, 13-24. doi: 10.1007/s10333-010-0236-0

Tuong, T. P. (1999). Productive water use in rice production, opportunities and limitations. J Crop Prod. 2, 241-264. doi: 10.1300/J144v02n02_10

Tuong, T. P.,., Bouman, B. A. M., and Mortimer, M. (2005). More rice less water, integrated approaches for increasing water productivity in irrigated rice-based systems in Asia. Plant Prod. Sci. 8, 231-241. doi: 10.1626/pps.8.231

UNCCD (2014). United Nations Convention to Combat Desertification, The Invisible Frontline. Available online at: http://www.unccd.int/Lists/ SiteDocumentLibrary/Publications/NEW_Invisible_\%20Front_Line_\%20EN. pdf (Accessed May 29, 2017).

Wissuwa, M., Ismail, A. M., and Graham, R. D. (2008). Rice grain zinc concentrations as affected by genotype native soil-zinc availability and zinc fertilization. Plant Soil 306, 37-48. doi: 10.1007/s11104-007-9368-4

Xu, X., McGrath, Y. S. P., Meharg, A. A., and Zhao, F. J. (2008). Growing rice aerobically markedly decreases arsenic accumulation. Environ. Sci. Technol. 42, 5574-5579. doi: 10.1021/es800324u

Yadav, S. E., Humphreys, E., Li, T., Gill, G., and Kukal, S. S. (2012). Evaluation of tradeoffs in land and water productivity of dry seeded rice as affected by irrigation schedule. Field Crops Res. 128, 180-190. doi: 10.1016/j.fcr.2012.01.005

Yang, J. K., Liu, Z., Wang, Y., and Zhang, J. (2007). Water-saving and highyielding irrigation for lowland rice by controlling limiting values of soil water potential. J. Integr. Plant Biol. 49, 1445-1454 doi: 10.1111/j.1672-9072.2007. 00555. $\mathrm{x}$

Yang, J., and Zhang, J. J. (2010). Crop management techniques to enhance harvest index in rice. J. Exp. Bot. 61, 3177-3189. doi: 10.1093/jxb/erq112

Yang, J., Zhou, Q., and Zhang, J. (2017). Moderate wetting and drying increases rice yield and reduces water use, grain arsenic level, and methane emission. Crop J. 5, 151-158. doi: 10.1016/j.cj.2016.06.002

Yang, Y., Zhang, F. S., Li, H. F., and Jiang, R. F. (2009). Accumulation of cadmium in the edible parts of six vegetable species grown in Cd-contaminated soils. J. Environ. Manage. 90, 1117-1122. doi: 10.1016/j.jenvman.2008.05.004

Yao, F. X., Huang, J. L., Cui, K. H., Nie, L. X., Xiang, J., and Liu, X. J. (2012). Agronomic performance of high-yielding rice variety grown under alternate wetting and drying irrigation. Field Crops Res. 126, 16-22. doi: 10.1016/j.fcr.2011.09.018

Zhang, H., Chen, T., Wang, Z., Yang, J., and Zhang, J. (2010). Involvement of cytokinins in the grain filling of rice under alternate wetting and drying irrigation. J. Exp. Bot. 61, 3719-3733. doi: 10.1093/jxb/erq198

Zhang, H., Xue, Y., Wang, Z., Yang, J., and Zhang, J. (2009). An alternate wetting and moderate soil drying regime improves root and shoot growth in rice. Crop Sci. 49, 2246-2260. doi: 10.2135/cropsci2009.02.0099

Zhang, Y., Tang, Q., Peng, S., Xing, D., Qin, J., Laza, R. C., et al. (2012). Water use efficiency and physiological response of rice genotypes under alternate wetting and drying conditions. Sci. World J. 2012, 1-10. doi: 10.1100/2012/ 523706

Conflict of Interest Statement: The authors declare that the research was conducted in the absence of any commercial or financial relationships that could be construed as a potential conflict of interest.

Copyright (๔ 2017 Sandhu, Subedi, Yadaw, Chaudhary, Prasai, Iftekharuddaula, Thanak, Thun, Battan, Ram, Venkateshwarlu, Lopena, Pablico, Maturan, Cruz, Raman, Collard and Kumar. This is an open-access article distributed under the terms of the Creative Commons Attribution License (CC BY). The use, distribution or reproduction in other forums is permitted, provided the original author(s) or licensor are credited and that the original publication in this journal is cited, in accordance with accepted academic practice. No use, distribution or reproduction is permitted which does not comply with these terms. 